\title{
Experimental Study of Formation of Future Philologists' Professional Competence by Means of Internet Technologies
}

\author{
Serhiy Danylyuk* \\ Conversational English Department, Educational-Scientific Institute of Foreign Languages, Bohdan Khmelnytsky National University \\ at Cherkassy, Cherkassy, Ukraine \\ *Corresponding author: sedan@bigmir.net
}

Received September 27, 2013; Revised October 10, 2013; Accepted November 16, 2013

\begin{abstract}
The paper deals with the highlighting of specific features of the introduction of the model of formation of future philologists' professional competence by means of Internet technologies in the educational process. For this purpose it is necessary to solve the following tasks: 1 ) to perform pedagogical diagnostics of criteria and indicators of formation of future philologists' professional competence; 2) to determine content characteristics of levels of formation of future philologists' professional competence on the basis of the singled out criteria and indicators; 3 ) to implement the experimental content and methods of the additional training of students (on the basis of the author's course "Information Technologies in the Educational Process"); 4) to diagnose levels of formation of future philologists' professional competence by means of Internet technologies and to make a comparative analysis of the obtained results with the results of the ascertaining phase of the pedagogical experiment. Diagnostic and statistical methods of research are applied in the paper.
\end{abstract}

Keywords: professional competence, forming experiment, ascertaining experiment

Cite This Article: Serhiy Danylyuk, "Experimental Study of Formation of Future Philologists' Professional Competence by Means of Internet Technologies." American Journal of Educational Research 1, no. 11 (2013): 484-489. doi: 10.12691/education-1-11-5.

\section{Introduction}

Singling out the criteria and indicators of formation of future philologists' professional competence makes it possible to diagnose the detection of the levels of this type of competence. The term "diagnosis" requires clarification of its content. It is interpreted as a recognition of a state of the certain object or system by means of quick registration of their essence parameters and their further admission to a specific diagnostic category for the prediction of their behavior and decision-making on the expected impact on this behavior to change it in the desired direction [[5], p. 6]. The notion of "diagnosis" correlates with the term "diagnostic work", which, according K. Ingenkamp [[4], p. 98], we understand the process by which the teacher, using or not using the diagnostic tools supervises students and conducts questioning, observations and works out questionnaires and reports the results to describe the behavior, to explain their motives or to predict their behavior in future, following the necessary scientific criteria of quality.

In our study the concept of "educational diagnosis" is actualized, which is interpreted as getting information about the state and development of the learning process, revealing conditions, advantages and disadvantages of this process, identification of ways of increasing its efficiency and improvement of vocational training in accordance to the intended purpose [[8], p. 129]. Pedagogical diagnostics is also seen as a process, which is a part of the scientific management system, directly connected with the defining of knowledge and skills, development of upbringing, evaluation of the actual students' behavior [[6], p. 145]. Thus, the pedagogical diagnostics is simultaneously both a special branch of pedagogical knowledge and the teacher's specific practical activities, the task of which is to study the course and results of the pedagogical process for its improvement [[2], p. 251].

In this paper by pedagogical diagnostics, according to $\mathrm{E}$. V. Tokar [[7], p. 491], we mean obtaining and analyzing information about the status, the development and current condition of the educational process, its results, identification of its advantages and disadvantages, factors that will influence its efficiency and performance. The purpose of pedagogical diagnostics is not only to determine the level of knowledge and skills of subjects of the educational process, but also in performing the analysis of conditions of conducting the current didactic process and their direct impact on the level of training, and in prediction of further development of the process of getting knowledge, improving future philologists' skills, as well as management of the training process in general.

For the pedagogical experiment its objectives and tasks were defined, criteria and indicators of future philologists' professional competence were outlined, the characteristics 
of the levels of formation of future philologists' professional competence (low, medium, high) were defined on the basis of the singled out criteria and indicators, the evaluation scale according to the levels of formation of future philologists' professional competence was defined (see Table 1), methods of research were worked out. The control group (CG) and experimental group (EG) were formed: KG - 293 persons, EG - 587 persons.

Table 1. Levels of Formation of Future Philologists' Professional Competence

\begin{tabular}{|c|c|c|c|}
\hline Level & low & medium & high \\
\hline Points & $40-60$ & $60-80$ & $80-100$ \\
\hline
\end{tabular}

\section{Pedagogical Experiment and Its Results}

Detection of effectiveness of the process of formation of future philologists' professional competence by means of Internet technologies requires proper implementation of research, which is realized through the pedagogical experiment. The pedagogical experiment is a kind of the educational process, organized to observe the pedagogical phenomena under controlled conditions. According to O. E. Zhosan, the main features of the pedagogical experiment, which at the same time characterize its essence, are [3, p. 26]: a) making some changes in the educational process according to the plan and the research hypothesis; b) creating conditions in which one can clearly see the relationship between different aspects of the educational process; c) taking into account the results of the educational process and the formulation of definitive conclusions. In the study of the formation of future philologists' professional competence two phases of pedagogical experiment were conducted: 1) ascertaining; 2) forming. For each of these phases the aim, the objectives and methods were defined.

\subsection{Contents of the Ascertaining Phase of the Pedagogical Experiment}

The objectives of the experimental work on the ascertaining phase of the pedagogical experiment is the selection of complex diagnostic procedures for: 1) identifying the prerequisites for using Internet technologies in the educational process by both teachers and students; 2) determination of the level of future philologists' motivation to use Internet technologies in their learning activities; 3) defining the levels of formation of future philologists' professional competence; 4) conducting the research using chosen diagnostic procedures.

880 students from different regions of Ukraine took part in the experiment.

In the ascertaining stage of the pedagogical experiment two phases are combined. The purpose of the first (founding) stage is the identification of prerequisites for the usage of Internet technologies by both teachers and students in the educational process, the analysis of theoretical and practical training of teachers and students to use Internet technologies. At the first phase of the ascertaining experiment questioning of both (teachers and students) as well as practical tasks were used.

The purposes of the second (diagnostic) phase of the pedagogical experiment are: 1) the determination of the level of students' motivation to use Internet technologies in their learning activities; 2) the determination of the level of student' motivation to learn foreign languages using Internet technologies. At the second stage such methods as questionnaires and interviews were used.

\subsubsection{Statistical Analysis of the Results of the Ascertaining Experiment}

One of the goals of the ascertaining experiment was to identify the prerequisites of usage of Internet technologies in the educational process with the help of questionnaires given to both teachers and students. The analysis of the questioning of teachers suggests that 76 per cent of the respondents have the opportunity to use a computer with access to the Internet in their professional activities, and 24 per cent of teachers do not have this opportunity.

The usage of Internet technologies in teaching a foreign language is considered to be prospective by 82 per cent of respondents. In their turn, 16 per cent of respondents reject the prospects of their usage, and the rest couldn't answer this question. Usage of Internet technologies is considered to be the most effective in teaching reading (82 per cent) and writing (59 per cent of respondents). It is also noted that the usage of Internet technologies can be effective in teaching speaking (28 per cent) and listening (28 per cent). Namely in the formation of lexical skills, as 90 per cent of respondents consider, the usage of Internet technologies is considered to be the most effective.

A separate set of questions concerned the usage by teachers the opportunities of the Internet for teaching foreign languages. The results indicate that 50 percent of respondents use the Internet as a source of obtaining professional information. However, 50 per cent of respondents use e-mail. Accordingly, 38 per cent of teachers do not use any opportunities of the Internet. Email serves primarily to receive, exchange, distribute materials, articles, reports, theses, etc. (49 per cent). 46 per cent of teachers who participated in the questioning used e-mail as a means of communication with students and colleagues from Ukraine and abroad. Thus 27 per cent of the respondents are experiencing the need to communicate with students via the Internet. In their turn, 54 per cent of teachers do not feel such a need, and the rest (19 per cent) could not answer the question.

It is clear that the integration of Internet technologies into the educational process changes the teacher's role. According to 47.3 per cent of respondents, the teacher acts as a facilitator. Accordingly, 47.3 per cent of respondents believe that the teacher acts as a consultant. However, 29.7 per cent of the teachers took the role of a leader, and 21.6 per cent - the role of an assistant. 29.7 per cent of respondents were unable to define the role of the teacher in the implementation of Internet technologies in the educational process.

The necessity of the existence of a personal website or webpage confirmed 27 per cent of teachers. In their turn, 54 per cent of respondents indicated that they had no such a necessity, and 19 per cent of respondents could not answer the question. 
The teachers, who took part in the experiment, expressed their views on the problems that hinder the effective implementation of Internet technologies in the educational process. The most important ones include financial problems (lack of proper facilities, lack of public funding) and organizational-and-methodological problems (lack of teaching materials, the problem of training teachers and students to work in the Internet, etc.). Some technical and psychological problems (existence of psychological barriers, skepticism about the innovation , the lack of widespread access to the Internet, etc.) are also specified.

In this regard, 73 per cent of respondents expressed a desire to learn more about online resources for teachers of foreign languages and undergo training for improving the ability to use Internet technologies in professional activities (49 per cent).

As for questioning students, it was conducted with the purpose of: a) identification of opportunities for students to use a computer with access to the Internet in their learning activities; b) investigation the students' opinion about the prospects of applying Internet technologies in teaching foreign languages; c) identification of the students' need to communicate with teachers via the Internet; d) determining the students' point of view on the necessity for teachers to have their own website or webpage.

The results of the questioning of students showed that 88 per cent of respondents have an opportunity to use a computer with access to the Internet in the learning process, but 12 per cent of students do not have this opportunity.

75 per cent of respondents consider the usage of Internet technologies in teaching foreign languages to be prospective. Consequently, 20 per cent of students denied this prospectiveness, and a small number of respondents (5 per cent) failed to answer this question.

The necessity to communicate with the teacher via the Internet experience about 38 per cent of the students, who participated in the questioning. In their turn, 54 per cent of respondents do not feel such a necessity. However, about 8 per cent of respondents did not express their point of view. Approximately the same results were fixed as for students' opinions about the necessity for teachers to have their personal websites or webpages.

For teachers the corresponding figures are: a) the question on the usage of a computer with access to the Internet in the educational process (76 per cent - "yes", 24 per cent - "no"); b) the question on the prospects of elearning in teaching foreign languages (82 per cent - "yes", 16 percent - "no", 2 per cent - "it’s difficult to answer"); c) the question on the need to communicate with students via the Internet (27 per cent - "yes" , 54 per cent - "no", 19\% - "it's difficult to answer").

The results are presented in the table (see Table 2).

Table 2. The Results of Questioning of Future Philologists Concerning Detection of Prerequisites for Usage of Internet Technologies in the Educational Process (the Ascertaining Experiment)

\begin{tabular}{|c|c|c|c|c|c|c|c|c|}
\hline Indicator & $\begin{array}{c}\text { Possibility } \\
\text { to use a } \\
\text { computer, } \\
\text { per cent }\end{array}$ & \multicolumn{3}{|c|}{$\begin{array}{c}\text { Prospectiveness of } \\
\text { Internet technologies, } \\
\text { per cent }\end{array}$} & \multicolumn{4}{|c|}{$\begin{array}{c}\text { Communication via } \\
\text { the Internet, per cent }\end{array}$} \\
\hline Answer & yes & no & yes & no & $\begin{array}{c}\text { don’t } \\
\text { know }\end{array}$ & yes & no & $\begin{array}{c}\text { don’t } \\
\text { know }\end{array}$ \\
\hline Teachers & 76 & 24 & 82 & 16 & 2 & 27 & 54 & 19 \\
\hline Students & 88 & 12 & 75 & 20 & 5 & 38 & 54 & 8 \\
\hline
\end{tabular}

Among the respondents, who have an opportunity to use a computer with access to the Internet in their educational activities, teachers make up 46 per cent, but students - 54 per cent. However, among those who do not have this opportunity, 66.7 per cent - teachers, but 33.3 per cent - students. Among the respondents who consider the usage of Internet technologies in teaching foreign languages to be prospective, 52.2 per cent are teachers, but students -47.8 per cent. In their turn, among respondents who feel the necessity to communicate via the Internet, teachers make up 41.5 per cent, but students - 58.5 per cent. Accordingly, those who consider such communication to be unnecessary, both teachers and students make up 50 per cent. Finally, among those who couldn't answer that question, we recorded 70.4 per cent of teachers, but 29.6 per cent of students.

Heterogeneity, observed in the assessment of the same parameters by teachers and students, is caused by psychological, organizational, methodological, technical, financial and other factors.

Another aim of the ascertaining experiment was to determine by questioning the students the level of their motivation to the usage of Internet technologies in their learning activities. Evaluation of the significance of some of those reasons is performed by a seven-point scale (in ascending order of importance motif). According to the assessment scale, the levels of motivation were defined (see Table 3).

Table 3. The Results of Questioning of Future Philologists Concerning Detection of Prerequisites for Usage of Internet Technologies in the Educational Process (the Ascertaining Experiment)

\begin{tabular}{|c|c|c|c|}
\hline Level & low & medium & high \\
\hline \multirow{2}{*}{ Points } & $1,00-3,99$ & $4,00-5,99$ & $6,00-7,00$ \\
\cline { 2 - 4 } & 2,50 & 4,50 & 6,50 \\
\hline
\end{tabular}

The empirical data about the levels of motivation to the usage of Internet technologies in the training of future philologists at the stage of input control is shown in the table (see Table 4) and on the diagrams (see Figure 1).

Table 4. Levels of Motivation of Future Philologists to the Usage of Internet Technologies in the Learning Activities (the Ascertaining Experiment)

\begin{tabular}{|c|c|c|c|c|}
\hline & Level & low & medium & high \\
\hline \multirow{2}{*}{\multicolumn{2}{|c|}{ Points }} & $1,00-3,99$ & $4,00-5,99$ & $6,00-7,00$ \\
\hline & & 2,50 & 4,50 & 6,50 \\
\hline \multirow{4}{*}{ 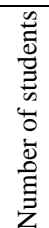 } & $\begin{array}{l}\text { CG }(X) \\
n_{1}=293 \\
\end{array}$ & 35 & 135 & 123 \\
\hline & $\begin{array}{l}\mathrm{EG}(y) \\
n_{2}=587\end{array}$ & 74 & 272 & 241 \\
\hline & & 109 & 407 & 364 \\
\hline & & 109 & 516 & 880 \\
\hline
\end{tabular}

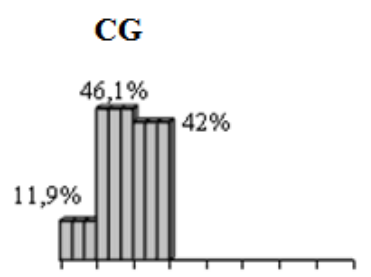

L.1. M.1. H.1.

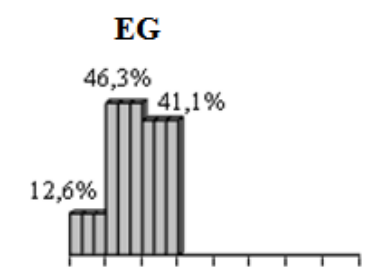

L.1. M.1. H.1.
Figure 1. Levels of Motivation to Use Internet Technologies in the Training of Future Philologists at the Stage of Entrance Control 
Analysis of the results of the ascertaining experiment is performed according to the following scheme:

a) the checking of the qualitative homogeneity of the groups under study (Wilcoxon's test [[1], p. 247]);

b) the finding of basic numerical characteristics of samples: 1$)$ the sample mean $(\bar{x}) ; 2)$ the variance $\left(D_{X}\right)$ and the average deviation $\left(\sigma_{X}\right)$; 3 ) the corrected variance $\left(S_{X}^{2}\right)$ and the standard deviation $\left.\left(S_{X}\right) ; 4\right)$ the accuracy of the assessment of the arithmetical mean $(\delta), 5)$ the confidence interval $(\bar{x}-\delta ; \bar{x}+\delta)$. Calculations are performed according to the method from [[1], p. 157, 181187]);

c) the checking of normality of general populations (Pearson's criterion [[1], p. 251]);

d) the checking of the equality of general variances (Fisher-Snedekor's criterion [[1], p. 207]);

e) the comparison of the average samples in the groups under study (Student's test [[1], p. 215]). The criterion for a given level $\alpha$ determines the significance of difference of the average samples in EG and CG. The criterion is used if normality of distribution of general populations and equality of their variances. This explains the presence of points c) and d) respectively in the research scheme.

After the conducted studying of students' motivation to use Internet technologies in their learning activities the following results were obtained:

a) the homogeneity of samples (the qualitative homogeneity of groups under study) (Wilcoxon's test [[1], p. 249]):

1) the level of significance: $\alpha=0,05$.

2) the volume of samples: $n_{1}=285, n_{2}=587$ (it is assumed that the first sample is less in volume);

3) The null hypothesis: the samples are homogeneous;

the competing hypothesis: the samples are nonhomogeneous;

the critical area - double-sided;

4) The lower critical point:

$w_{\text {ниж.кр. }}=\left[\frac{\left(n_{1}+n_{2}+1\right) n_{1}-1}{2}-z_{\kappa p .} \cdot \sqrt{\frac{n_{1} n_{2}\left(n_{1}+n_{2}+1\right)}{12}}\right]$.

$z_{\kappa p}$. we find in the table of Laplace's function using the equation $\Phi\left(z_{\kappa p .}\right)=(1-\alpha) / 2$ ([1, p. 389-390]). In our case, $z_{\kappa p}=1,96, w_{\text {ниж.кр. }}=122101$

5) The upper critical point:

$$
w_{\text {верх.кр. }}=\left(n_{1}+n_{2}+1\right) n_{1}-w_{\text {ниж.кр. }}=136032 .
$$

6) The general variational series:

$$
1 \ldots 109110 \ldots 516517 \text {... } 880 .
$$

7) The observed value of the criterion (the sum of ordinal numbers of the first sample in the general variational series):

$$
w_{\text {cnocm. }}=130095 \text {. }
$$

Since the observed value of the criterion does not exceed the critical area ( $\left.w_{\text {ниж.кр. }}<w_{\text {сnост. }}<w_{\text {верх.кр. }}\right)$, the null hypothesis of homogeneity of the sample is not refuted. CG and EG are qualitatively similar.

b) basic numerical characteristics:
1) the control group $(C G-X)$ :

$$
\begin{aligned}
& \bar{X}=5,10 ; \quad D_{X}=1,803 ; \sigma_{X}=1,343 ; \\
& S_{X}^{2}=1,809 ; S_{X}=1,345 ; \delta_{X}=0,15
\end{aligned}
$$

(4.95, 5.25) - confidence interval.

2) the experimental group $(E G-Y)$ :

$$
\begin{aligned}
& \bar{y}=5,07 ; \quad D_{y}=1,808 ; \sigma_{y}=1,345 ; \\
& S_{y}^{2}=1,814 ; \quad S_{y}=1,347 ; \quad \delta_{y}=0,16
\end{aligned}
$$

(4.91, 5.23) - CI.

c) the comparison of variance (Fisher-Snedekor's criterion):

1) the level of significance $\alpha=0,05$, the null hypothesis: variances are the same; the competing hypothesis: variances are different;

2) the observed value of the criterion (the relation of the greater corrected dispersion to smaller one):

$$
F_{\text {cnocm. }}=\frac{S_{L}^{2}}{S_{M}^{2}}=\frac{1,814}{1,809}=1,01
$$

3) the number of degrees of freedom:

$$
k_{1}=587-1=586 ; k_{2}=292 ;\left(k_{1} \text { corresponds to } S_{\bar{B}}^{2}\right) \text {; }
$$

4) the critical (tabular) value of the criterion:

$$
F_{\kappa p}\left(0,05 ; k_{1}, k_{2}\right)=1,90 \text {. }
$$

Since $F_{\text {cnocm }}<F_{\kappa p}$, the null hypothesis of homogeneity of variances is not refuted. The quality assessment is the same in both groups.

d) the comparison of the average sample (Student's test):

1) the volume of samples, the sample mean, the variance corrected:

$$
\begin{aligned}
& n_{1}=293 ; S_{x}^{2}=1,809 ; \quad \bar{x}=5,10 \\
& n_{2}=587 ; S_{y}^{2}=1,814 ; \bar{y}=5,07
\end{aligned}
$$

the number of degrees of freedom:

$$
k=n_{1}+n_{2}-2=878
$$

2) the observed value of the criterion:

$$
\begin{aligned}
& T_{\text {cnocm. }} \\
& =\frac{5,10-5,07}{\sqrt{292 \cdot 1,809+586 \cdot 1,814}} \cdot \sqrt{\frac{293 \cdot 587 \cdot 878}{880}}=0,27
\end{aligned}
$$

3) the critical number of the criterion:

$$
t_{\kappa p}(0,05 ; 576)=1,96 \text {. }
$$

Since $\left|T_{\text {cnocm. }}\right|<t_{\kappa p .}$, the average sample differs insignificantly.

Key figures of the CG and EG, regarding students' motivation to use Internet technologies in their learning activities, are shown in the table (see Table 5).

Another objective of the ascertaining experiment was to determine the students' motivation levels to the study of foreign languages using Internet technologies by means of questioning students. The grading scale and the levels of motivation are the same as in the previous case (see Table 2). 
Table 5. Basic Indicators of Future Philologists' Motivation to Learning Activities in CG and EG (the Ascertaining Experiment)

\begin{tabular}{|c|c|c|c|c|c|c|c|c|}
\hline & \multirow{2}{*}{ 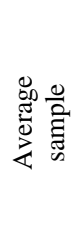 } & \multirow{2}{*}{ 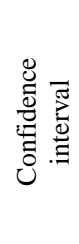 } & \multirow{2}{*}{ 己 } & \multirow{2}{*}{ 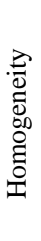 } & \multirow{2}{*}{ 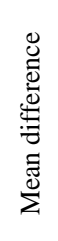 } & \multicolumn{2}{|c|}{$\begin{array}{c}\text { The value } \\
\text { of } t- \\
\text { criterion }\end{array}$} & \multirow{2}{*}{ 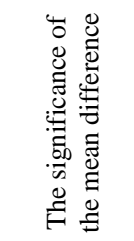 } \\
\hline & & & & & & 플 & 预 & \\
\hline CG & 5.10 & $\begin{array}{c}\text { (4.95; } \\
5.25)\end{array}$ & 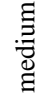 & \multirow{2}{*}{ 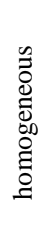 } & \multirow{2}{*}{0.03} & \multirow{2}{*}{0.27} & \multirow{2}{*}{1.96} & \multirow{2}{*}{ insignifcan } \\
\hline EG & 5.07 & $\begin{array}{c}\text { (4.91; } \\
5.23)\end{array}$ & 䍖 & & & & & \\
\hline
\end{tabular}

The empirical data about the levels of future philologists' motivation to learn foreign languages by means of Internet technologies is shown in the table (see Table 6) and on the diagram (see Figure 2).

Table 6. Levels of Motivation of Future Philologists to Studying Foreign Languages by Means of Internet Technologies (the Ascertaining Experiment)

\begin{tabular}{|c|c|c|c|c|}
\hline & Level & low & medium & high \\
\hline \multirow{2}{*}{\multicolumn{2}{|c|}{ Points }} & $1,00-3,99$ & $4,00-5,99$ & $6,00-7,00$ \\
\hline & & 2,50 & 4,50 & 6,50 \\
\hline \multirow{4}{*}{ 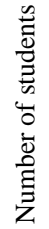 } & $\begin{array}{l}\mathrm{CG}(X) \\
n_{1}=293 \\
\end{array}$ & 37 & 147 & 109 \\
\hline & $\begin{array}{l}\mathrm{EG}(y) \\
n_{2}=587\end{array}$ & 74 & 336 & 177 \\
\hline & & 111 & 483 & 286 \\
\hline & & 111 & 584 & 880 \\
\hline
\end{tabular}

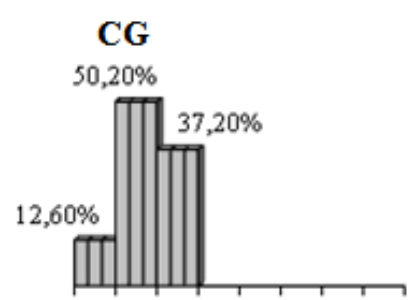

L.1. M.1. H.1.

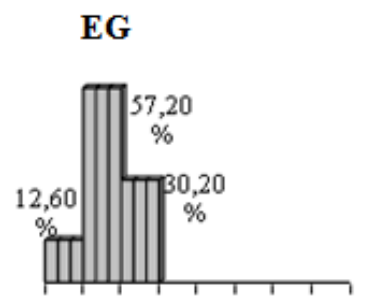

L.1. M.1. H.1.
Figure 2. Levels of Future Philologists Motivation to Study Foreign Languages by Means of Internet Technologies at the Stage of Entrance Control

After studying the students' motivation to study foreign languages by means of Internet technologies the following results were obtained:

a) homogeneity of samples (qualitative homogeneity of groups under study):

The level of significance, the null and the competing hypotheses, the boundaries of the critical area are the same as in the study of levels of motivation to use Internet technologies in the training of future philologists.

1) The general variational series:

$$
1 \text {... } 111112 \ldots 594595 \text {... } 880 .
$$

2) The observed value of the criterion:

$$
w_{\text {cnocm. }}=134350 \text {. }
$$

3) the critical point:

$$
w_{\text {ниж.кр. }}=122101 ; w_{\text {верх.кр. }}=136032 .
$$

Since the observed value of the criterion does not exceed the critical area $\left(w_{\text {ниж.кр. }}<w_{\text {спост. }}<w_{\text {верх.кр. }}\right)$, the null hypothesis of homogeneity of the sample is not refuted. CG and EG are qualitatively similar.

b) basic numerical characteristics:

1) the control group $(\mathrm{CG}-\mathrm{X})$ :

$$
\begin{aligned}
& \bar{X}=4,99 ; \quad D_{X}=1,766 ; \sigma_{X}=1,329 ; \\
& S_{X}^{2}=1,772 ; S_{X}=1,331 ; \delta_{X}=0,15 ;
\end{aligned}
$$

(4.84, 5.14) - confidence interval.

2) the experimental group (EG - Y):

$$
\begin{aligned}
& \bar{y}=4,85 ; \quad D_{y}=1,598 ; \sigma_{y}=1,264 ; \\
& S_{y}^{2}=1,603 ; \quad S_{y}=1,266 ; \delta_{y}=0,15 ;
\end{aligned}
$$

(4.70, 5.00) - confidence interval.

c) the comparison of variance (Fisher-Snedekor's criterion):

The research methodology is the same as in the study of levels of motivation to use Internet technologies in the training of future philologists, that's why the explanations are given very briefly.

1) the observed value of the criterion:

$$
F_{\text {cnocm. }}=\frac{S_{\bar{L}}^{2}}{S_{M}^{2}}=1,01, F_{\kappa p}(0,05 ; 292,586)=1,90 .
$$

$F_{\text {cnocm }}<F_{\kappa p}$. The sample variances differ insignificant (accidentally).

d) comparison of the average sample (Student's test):

1) the observed value of the criterion:

$$
\begin{aligned}
& T_{\text {cnocm. }} \\
& =\frac{4,99-4,85}{\sqrt{292 \cdot 1,772+586 \cdot 1,603}} \cdot \sqrt{\frac{293 \cdot 587 \cdot 878}{880}}=1,29
\end{aligned}
$$

\begin{tabular}{|c|c|c|c|c|c|c|c|c|}
\hline & \multirow{2}{*}{ 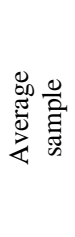 } & \multirow{2}{*}{ 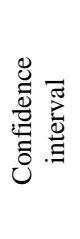 } & \multirow{2}{*}{$\stackrel{\Xi}{\beth}$} & \multirow{2}{*}{ 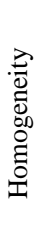 } & \multirow{2}{*}{ 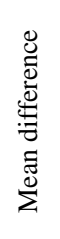 } & \multicolumn{2}{|c|}{$\begin{array}{l}\text { The value } \\
\text { of } t- \\
\text { criterion }\end{array}$} & \multirow{2}{*}{ 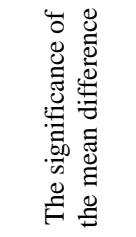 } \\
\hline & & & & & & 뮬 & : & \\
\hline CG & 4.99 & $\begin{array}{c}\text { (4.84; } \\
5.14)\end{array}$ & 苛 & \multirow{2}{*}{ 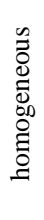 } & \multirow{2}{*}{0.14} & \multirow{2}{*}{1.29} & \multirow{2}{*}{1.96} & \multirow{2}{*}{ insignifcant } \\
\hline EG & 4.85 & $\begin{array}{l}(4.70 ; \\
5.00)\end{array}$ & $\underset{\Xi}{\Xi}$ & & & & & \\
\hline
\end{tabular}

2) the critical number of the criterion:.

$t_{\kappa p}(0,05 ; 878)=1,96$. The arithmetical mean differs insignificantly.

Key figures of CG and EG are shown in the table (see Table 7).

Table 7. Basic Indicators of Future Philologists' Motivation to Learning Activities in CG and EG (the Ascertaining Experiment)

\section{Results}

Having conducted the questioning of students and teachers about the identification of conditions for usage of 
Internet technologies in the educational process, we come to the conclusion that the vast majority of teachers (76 per cent) and students (88 per cent) has the opportunity to use a computer with access to the Internet in the educational process. The usage of Internet technologies in teaching foreign languages is considered to be prospective by 82 per cent of teachers and 75 per cent of students.

Using Internet technologies, teachers can be effective both in teaching certain types of language activities (reading, writing, speaking, listening) and the formation of skills (lexical, grammatical, phonetic).

Teachers use only some possibilities of the Internet for teaching foreign languages (as a source of professional information, e-mail, etc.). Over one third of the questioned teachers do not use the possibilities of the Internet.

The vast majority of teachers who took part in the questioning (70 per cent) said that the integration of Internet technologies into the educational process had changed the role of the teacher. However, 30 per cent of respondents were unable to identify the specific role of the teacher in that case.

The introduction of Internet technologies in the educational process in higher education remains ineffective because: a) the possibilities of the Internet for teaching foreign languages are seldom used; b) the teachers' role in integrating Internet technologies into the learning process is clearly understood; c) there is no adequate material resources and access to the Internet; d) the organizational methods of teaching should be improved.

The vast majority of teachers of foreign languages (73 per cent) considers it necessary to learn more about Internet resources and undergo training in improving the ability to use Internet technologies in their professional activities.

Accordingly, the analysis of the data of the questioning to determine the level of student's motivation to use Internet technologies in their learning activities shows that the most significant reasons are: the desire to become a professional, to get a degree and ensure the success of future career by means of Internet technologies (the grade point average is 6.41; about 42 per cent of the participants of the experiment), the motives of the medium level of importance were the students' desire to succeed and successfully continue their studies at further courses and to improve the ability to use Internet technologies in learning activities (the grade point average is 4.63, about 46 per cent of the respondents); the least significant motives were the desire to be an example for fellow students by ability to use Internet technologies, to get the parental approval , to avoid censure and punishment for bad training (the grade point average is 3.32 , about 12 per cent of the students).

Having analyzed obtained in the result of students' questioning data about the students' level of motivation to learn foreign languages by means of Internet technologies, we come to the conclusion that the most significant motives are deep and strong knowledge of foreign languages, the successful career, the work in a joint firm, mastering of foreign languages as a means of communication, successful examinations of foreign languages in high school (the grade point average is 6.28, 33.7 per cent of participants of the experiment), the motives of the medium level of importance were: getting of the second diploma of a translator, the review of literature and culture in the original language by means of Internet technologies, intellectual pleasure from learning foreign languages by means of Internet technologies, a trip to study abroad and to get an international certificate, the maintenance of the acquired knowledge, skills and abilities (the grade point average is 5.29 , about 53.7 per cent of respondents), the least significant motives for participants of the experiment were the students' striving to be the best in the academic group in the ability to use Internet technologies in their educational activities, the approval of parents and environment for such skills, to avoid censure and punishment for bad training (the grade point average is 3.55, 12 per cent of the respondents).

Thus, before conducting the forming experiment the principle of uniformity of quantitative and qualitative data in CG and EG is followed and it was found that the level of formation of future philologists' professional competence is low at this time. The average success rate in both groups is 57.0 points.

As a result, the CG and EG at the stage of the ascertaining experiment are qualitatively similar, and their numerical data are not significantly different.

\section{References}

[1] Gmurman, W. E, A Guide to the Solution of Problems in the Theory of Probability and Mathematical Statistics, High School, Moscow, 1979, 400 .

[2] Goncharenko, S. U, Ukrainian Pedagogical Dictionary, Lybid', Kyiv, 1997, 376.

[3] Zhosan, A. E, Pedagogical Experiment, Kirovohrad Regional Institute of Postgraduate Pedagogical Education named after Vasil' Sukhomlynskyy, Kirovohrad, 2008, 72.

[4] Ingenkamp, K, Pedagogical Diagnostics, Pedagogics, Moscow, 1991, 240.

[5] Kochetov, A. I, Educational Research, Ryazan' State Pedagogical Institute, Ryazan', 1975, 177.

[6] Slyepkan', Z. I, Scientific Foundations of Educational Process in High School, High School, Kyiv, 2005, 239.

[7] Tokar', Ye. B, "Role and Place of Pedagogical Diagnostics in Modern Educational Process", Teoretyko-metodychni problemy vykhovannya ditey ta uchnivs'koyi molodi, Imeks-LTD, Kirovohrad, №14, 486-496, 2010.

[8] Tsekhmistrova, H. S, Management in Education and Pedagogical Diagnostics, Publishing House "Word", Kyiv, 2005, 280. 